Historic, Archive Document

Do not assume content reflects current scientific knowledge, policies, or practices. 



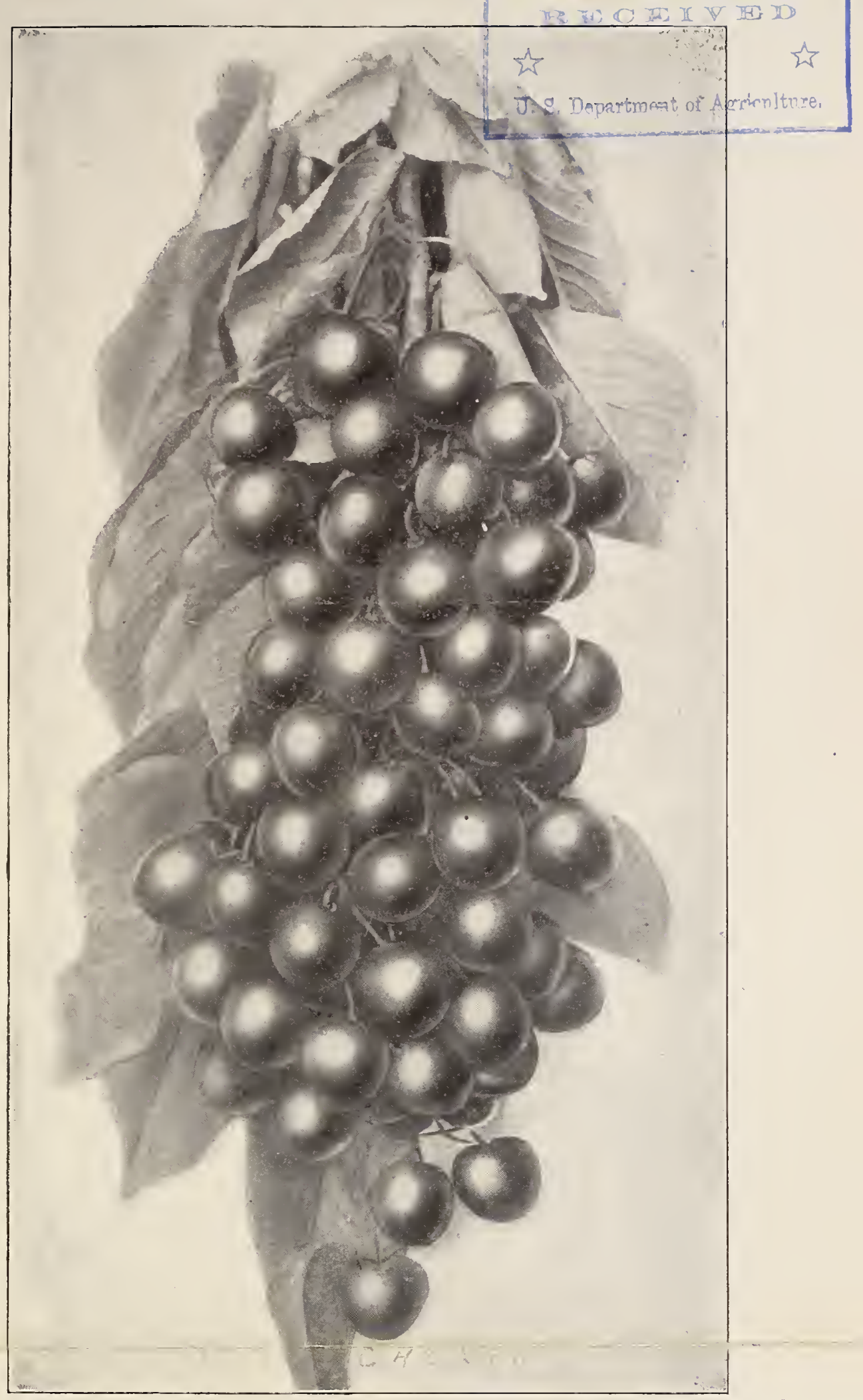

\section{"PAUL" CHERRY}

A new BLACK CHERRY showing most remarkable shipping qualities, having been repeatedly found in perfect condition after shipment of 26 days in closed box. It is the largest black cherry ever produced. In flavor it excels any other black cherry. It is the only black cherry that cans well. It ripens after all other cherries, so meets no opposition.

The trees have withstood almost zero weather, in northern exposure. It is never a shy bearer; the trees have never failed to fruit abundantly. A handsome uprigh grower, the fruit bunching on the limbs, making picking easy. The PAUL cherry originated on the ranch of E. V. D. Paul in the mountains of Mendocino County.

The entire stock of young trees is owned by the Leonard Coates Nursery Co., and no one else has any of the nursery stock. The exclusive right to introduce this wonderful cherry has been assigned to the Leonard Coates Nursery Co, and no one else is authorized to sell any trees.

$\because$ Write the Leonard Coates Nursery Co., Morganhill, Santa Clara Ccunty, California, for further particulars regarding the "PAUL" cherry.

Nursery stock will be available during the season of $190 \mathrm{~s}-09$. E. V. D. PAUL

Ukiah, California.

"The finest shipping cherry I have ever seen. Its great size. musual firmness, deep.

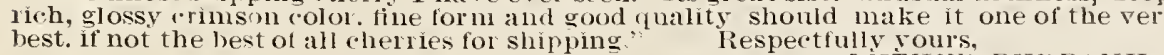
作

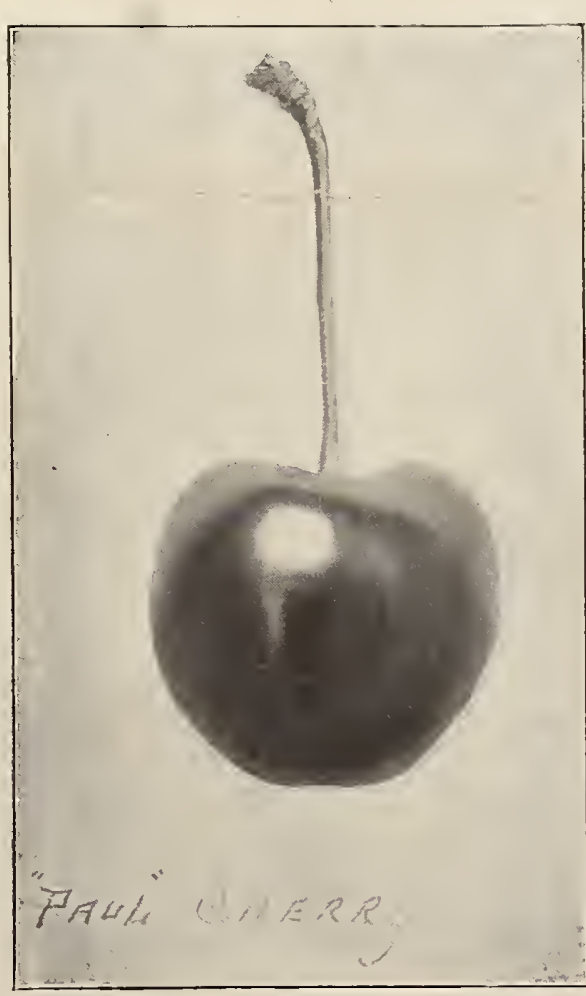

.- Your cherries are grand and justiry rariety should prove as productive everywhere as it does with you, I do

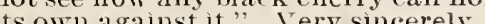

E.J. Wl(ksoN, Berkeley.

in or the college or

-This is the firest black cherry to
have ever seen, arevaging larger in (ize than elthel the black Tartarian in the market late, it will undoubtedly mover all time. as it hasthis season, liespectruly yours.

WETMORE BROS., I. $\rightarrow$. Wetmore, Ser:
. F -The finest black canning cherry have evel seen.

Manager Go san Jose.

And many more similar testinomial from well known men.

Prices of trees, 1 year old, $\$ 2.00$ each, $\$ 10.00$ per half dozen,

$\$ 18.00$ per dozen.

Leonard Coates Nursery Co.

INCORPORATED 


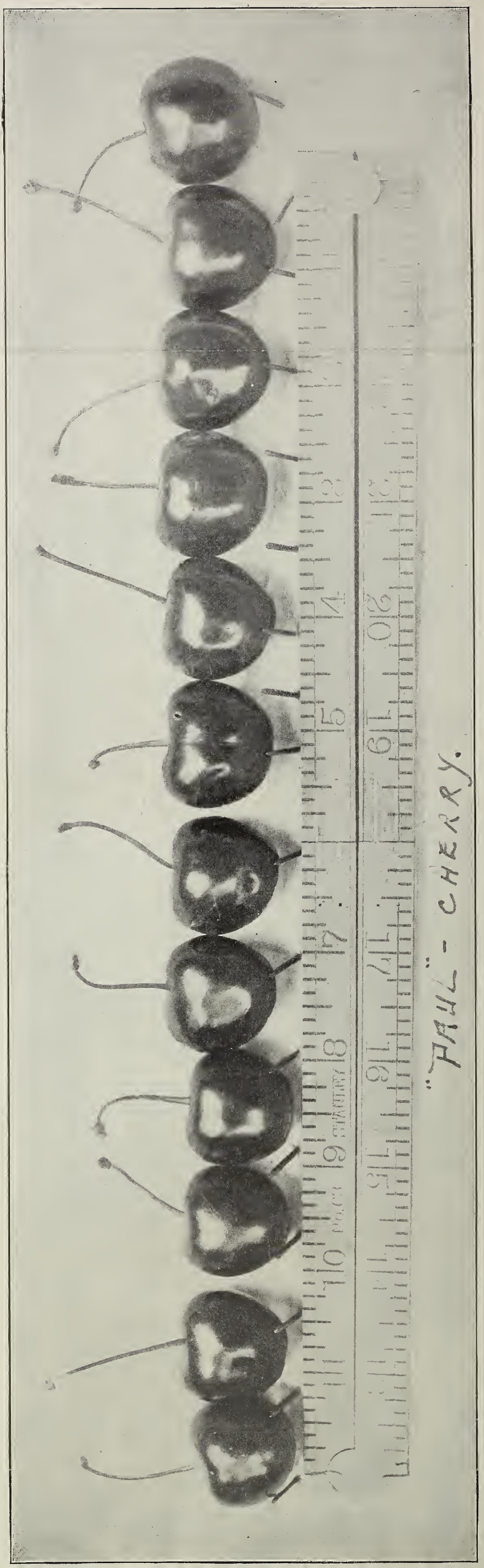

